\title{
Os sentidos do envelhecimento
}

GISELI GONTARSK ${ }^{80}$

\section{RESUMO}

Este artigo tem como objetivo principal discutir a experiência de envelhecimento de doze homens e mulheres, com idades entre 68 e 95 anos. A pesquisa de campo foi realizada na cidade de Mafra, no interior de Santa Catarina. A velhice é um fenômeno complexo, pois apresenta em sua essência uma ambiguidade: ao mesmo tempo em que aparece como sinônimo de doença, inatividade, dependência e declínio, essa etapa da vida também pode ser encarada como o tempo da liberdade, de conquistas e vivacidade. A pesquisa demonstrou que os significados atribuídos ao envelhecimento são variados, pois existem diversas formas de envelhecer, tanto positivas - melhoria da condição de vida; novas formas de sociabilidade -, quanto negativas - como sinônimo de doença, inscrevendo a velhice nos indivíduos. Mas as entrevistas revelaram ainda que há uma grande distância entre os discursos elaborados sobre o envelhecimento e a forma que os entrevistados efetivamente experimentam essa etapa da vida. Ao falar da velhice eles acabam negando sua condição de velho. Em contraposição a isso, quando os velhos pesquisados contam suas experiências cotidianas como um todo, eles se auto definem velhos. E nesse momento não é a velhice sinônimo de perda e decadência que está sendo mencionada e sim uma outra velhice, bem mais positiva, que considera sobretudo as trajetórias individuais.

Palavras-chave: Velhice, Experiência, Doença, Trabalho.

\section{INTRODUÇÃO}

Há algumas décadas o Brasil tem vivenciado o fenômeno do envelhecimento e com isso buscado formas de garantir o lugar desses "novos" sujeitos sociais. As lentes que observam a velhice são as mais variadas possíveis, identificando-a como o tempo da decadência e/ou da liberdade, da restrição e/ou do desfrute, ambiguidade essa que está presente inclusive nos discursos dos velhos quando falam si. Essa pesquisa trabalha a velhice sob a perspectiva das Ciências Sociais, que a compreende como uma construção social, o que significa que cada cultura, cada tempo histórico cria um sistema simbólico

\footnotetext{
${ }^{80}$ Mestre em Sociologia (UFPR/2012). Bacharel em Ciências Sociais (UFPR/2009). Membro do Grupo de Pesquisa em Sociologia da Saúde-CNPq/UFPR.
} 
próprio para representar o velho. Além disso, o envelhecimento é também uma construção subjetiva que varia de acordo com as trajetórias particulares de cada sujeito. A velhice é uma experiência plural, o que faz com que os sentidos atribuídos ao envelhecimento sejam igualmente variados. É também por considerar a velhice como uma experiência social que utilizamos o termo velho para nos referirmos a esses sujeitos, tentando justamente desconstruir a imagem pejorativa incorporada por esse termo em nossa sociedade.

A pesquisa de campo, que utilizou a técnica da entrevista semiestruturada, foi realizada com doze homens e mulheres com idades entre 68 e 95 anos, na cidade de Mafra, interior de Santa Catarina. A maior parte dos entrevistados são católicos, nasceram e foram criados em comunidades rurais, são ou foram casados, tiveram filhos, tem uma escolaridade baixa, são aposentados e possuem uma renda mensal em torno de dois salários mínimos.

As narrativas comprovam que há variadas formas de envelhecer. Mas elas também se agregam num ponto comum: a vida do velho é contada como uma luta. Os nossos narradores enfrentaram trabalho pesado da roça, dificuldade na criação dos filhos, as doenças e a busca pela cura, a distância da cidade. Se depararam com a morte, através da perda dos pais, dos irmãos, dos companheiros e também dos filhos, essa última considerada a mais dolorosa, por trazer a inversão da ordem da vida. Os velhos são, portanto, vencedores. Chegaram até a velhice é isso já uma vitória. Construíram uma família, conquistaram suas casas, a aposentadoria, saúde, educação dos filhos e respeito da comunidade em que vivem.

\section{VELHICE COMO NÃO LUGAR}

Na contemporaneidade, a velhice foi construída na dicotomia jovem/velho, onde o velho é visto como decadente, feio e inativo. Visão esta, que levada às últimas consequências, significa que a velhice é considerada um peso para o restante da sociedade. No contexto brasileiro, essa imagem negativa dos velhos dominou soberana até as duas últimas décadas do século $\mathrm{XX}$, e continua forte, devido ao discurso elaborado sobre a velhice na Geriatria, especialidade médica que inaugurou os estudos sobre velhice no país. Deste modo, a Gerontologia que deveria ser uma área de estudos que 
abarcasse as várias dimensões da categoria velhice, acabou ficando atrelada ao conhecimento elaborado pela Geriatria, que a entende como problema de fundo biológico. Segundo Neri (1991),

Cada vez mais é a Medicina, muito mais que as instituições legais e religiosa a responsável pela definição e o controle dos problemas sociais. Haja visto o que acontece hoje com as questões de saúde pública, de evasão e fracasso escolar, onde 'o culpado é a vítima'. O velho não é exceção: seu problema não é fruto da pobreza, das doenças e da inatividade, mas sim da senilidade, gerada por causas biológicas ou psicológicas (NERI, 1991: 58).

Diante dessa situação, continua Neri,

Os gerontólogos não só sucumbiram aos estereótipos culturais quanto á incompetência comportamental do idoso, como também contribuíram para fortalecê-lo ao institucionalizarem os estereótipos negativos sobre o velho, em nome da ciência (NERI, 1991: 57).

Foi no mesmo sentido da crítica de Neri à Gerontologia, que surgiram outros trabalhos sob as lentes das Ciências Sociais. Mesmo diante das inúmeras perspectivas que essas pesquisas sobre velhice apresentam, o traço que as aproxima é a denuncia elaborada sobre o não lugar da velhice no Brasil. Na literatura, o isolamento social provocado pela condição de velhice dos sujeitos foi estudado de diversos ângulos, mas sempre mantiveram como pano de fundo o debate sobre a ausência da velhice como um lugar social.

Segundo Debert (2010), o problema é que na sociedade contemporânea a juventude acabou virando um valor ideal. Ela descola-se da etariedade (ou a ideia de categoria etária) e erige-se como um valor em si. Para Debert, essa transformação implica em três processos: O primeiro é o "alargamento da faixa etária do segmento considerado jovem da população" o segundo é o "desdobramento das etapas mais avançadas do ciclo da vida em novas categorias etárias" (terceira idade, quarta idade e quinta idade); e o último é a "transformação da juventude em um valor que pode ser conquistado em qualquer etapa da vida através da adoção de formas de consumo e estilos de vida adequados" (uma pessoa pode ser considerada jovem aos quarenta, por exemplo) (DEBERT, 2010: 49). Em outro trabalho, Debert (2003) afirma que a consequência dessa transformação para a questão do envelhecimento é que o velho acaba sendo tratado como negligente, que envelheceu porque não adotou estilos de vida e consumo que conservassem a sua juventude. Essa compreensão leva a um movimento que a autora chama de reprivatização do 
envelhecimento, pois coloca a velhice no plano individual, culpando o sujeito por ter envelhecido. E neste sentido, sua preocupação é que "a velhice poderia novamente desaparecer do leque de preocupações sociais" (DEBERT, 2003: 154).

Em certa medida, a transformação da juventude num valor pôde ser verificada na nossa pesquisa de campo, sendo que os sujeitos entrevistados demonstraram grande dificuldade de se perceberem velhos. A maioria nega seu pertencimento à velhice e afirma: "Eu não sou velho!" Esta afirmação aparece nas narrativas de Euclides, Sebastião, Lourdes, Dolores, Joaquim, Olívia e Carmem.

Segundo Sebastião, a velhice retira todas as possibilidades de ação do sujeito: "Velho é quando fica lá, com o peso da idade, a pessoa não pode mais fazer nada, isso é velho. Eu, pra mim, a idade é isso aí. É o peso da idade que deixa velho, mas eu não me sinto velho" (Sebastião, 83 anos).

Para Estela, velho é aquele que perde sua autonomia, pois "não pode mais enxerga e nem caminha bem, tem que andar se apoiando, com a mão nas parede ou no que pode se agarrar, pra não cair" (Estela, 95 anos).

Euclides também apresenta uma linha semelhante de entendimento da velhice. Para ele, o fato de morar no asilo não faz dele um velho, pois

\begin{abstract}
Velhinho é quando perde a vontade de fazer exercício, da fisioterapia, de se movimentar e tudo. Quando ele se acomoda... fica só naquilo, parece que não tem mais coragem... Daí eu acho que ta mais pra velhinho! (Euclides, 68 anos).
\end{abstract}

Perceba-se que em ambos os discursos, mas principalmente na expressão "velhinho", utilizada por Euclides como uma maneira menos ofensiva de se referir ao velho, a velhice pode ser pensada como um tabu (Elias, 2001), ou seja, um lugar que deve constantemente ser empurrado pra longe de cada um dos indivíduos.

Esse movimento de afastamento da velhice cada vez mais pra perto da morte, afirma Britto da Motta (2002) também acontece quando trocamos o termo velho por idoso. Pois com a intenção de diminuir o preconceito em relação aos velhos chamando-os de idosos, as formas contemporâneas de gestão da velhice acabam por corroborar a visão negativa concebida a ela, minando a possibilidade de instituição de outras formas de envelhecimento. O termo "Terceira Idade", surgido na França - e rapidamente apropriado pelos brasileiros - trabalha nesse mesmo sentido. 
A identificação da velhice com a morte já havia sido discutida por Norbert Elias (2001). Segundo ele, para entender o que é envelhecer, é preciso reconhecer que, mesmo com todas as particularidades, de um modo geral a chegada da velhice instaura uma transformação fundamental na vida do sujeito, que o autor descreve como uma mudança de posição na estrutura social. O autor inicia o texto contando uma situação que aconteceu com ele na juventude:

Assisti a uma conferência de um físico muito conhecido em Cambridge. Ele entrou devagar, arrastando os pés, um homem muito velho. Eu me surpreendi pensando: 'Por que ele arrasta os pés assim? Por que não pode caminhar como um ser humano normal?' Na hora me corrigi: 'Não pode evitar, é muito velho.' (ELIAS [1983] 2001: 79).

Elias traz esse elemento para afirmar que esse é o tipo de reação dos "normais" em relação aos mais velhos. Ele explica que utiliza a expressão "normal" para se referir aos jovens, porque a velhice é muitas vezes percebida com um desvio à norma social. Segundo Elias, é esse deslocamento na posição social entre jovens e velhos que faz com que os primeiros não "compreendam" a velhice e "consciente ou inconscientemente, eles resistem à ideia de seu próprio envelhecimento e morte, tanto quanto possível" (ELIAS [1983] 2001: 80). Norbert Elias quer dizer com isso, que é compreensível que os jovens não entendam a velhice, assim como ele também não a entendia na sua juventude. Pois o envelhecimento só tem sentido a partir do momento que o indivíduo passa pela experiência de velhice, que é, sobretudo, uma experiência corporal.

Utilizando a ideia elisiana, de que a velhice provoca uma mudança de posição na estrutura social, para analisar os significados da velhice nos dados da nossa pesquisa, envelhecer pode ser pensado como o marco social e temporal que delimita a retirada dos sujeitos de cena. A velhice marcaria a morte social dos indivíduos, o que sublinha a ausência de um lugar para ela em nossa sociedade.

A compreensão de Joaquim e Dolores vai ainda mais longe, no sentido de delimitar o fenômeno da velhice, convertendo-o num não lugar. Nas palavras de Joaquim,

Ah, velho é aquele que não pode mais caminhar, e ta só deitado. Então isso chama-se velho e velhice. Mas eu acho que enquanto a gente pode caminhar, não ta aleijado, enxerga, escuta, então eu acho que ainda vale a pena viver. Eu me considero ainda não velho, não acabado (Joaquim, 74 anos).

E igualmente para Dolores, "velho é um trapo que a gente joga no lixo. Eu sou usada, mas não velha" (Dolores, 86 anos). As condições que definem a velhice nessas 
falas colocam a seguinte questão: Quê lugar ocuparia então a velhice nas suas vidas, haveria um lugar para ela? A resposta é não, pois negam o seu pertencimento a essa categoria. O fato é que a negação está tão enraizada que acaba por deslocar a velhice para fora das biografias. No caso dos cinco sujeitos que acabamos de apresentar, não há lugar para a velhice em suas vidas. Pelo menos não para essa velhice que habita os seus imaginários, expressadas nas suas falas, essencialmente ligada à doença, desânimo ou imobilidade. Velhice essa, que em última medida, acaba por simbolizar a retirada do indivíduo da cena social.

Mas como podemos compreender a atitude de negação do envelhecimento por parte dos entrevistados? Autoras como Britto da Motta (2002) e Debert (2010) levam a pensar que esse seria o modo que eles encontraram de se defender do estereótipo da velhice, justamente por ele ser tão restritivo e não oferecer espaço para outra velhice, mais positiva, a qual corresponde a maneira que os velhos pesquisados realmente vivenciam esse período. Como eles poderiam admitir uma velhice que anuncia a sua decadência, se não é essa a realidade de sua condição?

A expressão "Eu não sou velho!", demarca também a posição desses sujeitos frente a sociedade que os espreita. Mas quê posição é essa? Negando seu pertencimento a uma velhice que destitui o sujeito de sua humanidade, o velho faz um apelo: Eu não estou morto, eu estou vivo! E nesse sentido sua vida continua sendo uma batalha, a de provar que mesmo velho continua sendo homem. A atitude de negar a velhice aparece como alternativa, já que conquistar outro lugar para ela é um processo lento e que, mesmo que já tenha alcançado algumas vitórias, ainda está longe de ser uma velhice apropriada às necessidades e expectativas dessa população.

\section{SOCIABILIDADE NA VELHICE: OLHARES SOBRE O ENVELHECIMENTO}

Mas diante da constatação de que a velhice é um fenômeno plural, podemos dizer que há outras formas de vivenciar o envelhecimento, que não a sua falta de lugar social. Essas formas plurais e até contraditórias de vivenciar a velhice serão apresentadas a partir das formas de sociabilidade inauguradas com o envelhecimento.

No contexto brasileiro, Britto da Motta (2002) e Debert (2010) tem estudado a sociabilidade na velhice em paralelo ao processo de construção da identidade desse momento da vida. Essas autoras concluíram que, nos últimos anos, a velhice vem 
tomando contornos mais positivos, que desafiam o velho a construir sua identidade, considerando as possibilidades de viver plenamente essa etapa da vida.

Fundamentalmente é preciso reconhecer que com a chegada da velhice, a rotina dos idosos vai mudando, levando-os a conviver e interagir em novos espaços - passam a morar sozinhos, mudam para a casa dos filhos ou para o asilo, frequentam os grupos de terceira idade, se afastam do mundo do trabalho ou encontram outra atividade, entre outros. Na nossa pesquisa de campo três eventos apareceram como situações relevantes de constituição da sociabilidade na velhice: a viuvez, o asilo e os grupos de terceira idade - além, é claro, da aposentadoria, que já foi trabalhada. Vejamos como esses novos arranjos são fundamentais nas imagens que os idosos constroem sobre a velhice.

\section{VIUVEZ, TEMPO DE RECONSTRUÇÃO}

A maioria dos entrevistados iniciam as suas narrativas pelo casamento. Em geral, as mulheres casaram-se jovens, por volta dos 17 anos; com o primeiro namorado. Já os homens casaram-se mais velhos, por volta dos 25 anos. O casamento aparece como possibilidade de formação de uma nova família, do trabalho em conjunto para a aquisição de bens e criação dos filhos. A grande maioria dos entrevistados trabalhou na lavoura nos primeiros anos do casamento. Todos os casais tiveram filhos já no primeiro ano de união. A quantidade varia entre três e dez filhos por casal. Assim, o casamento para os entrevistados apresentou-se como parte de um projeto de vida.

Do universo de pesquisa formado por doze velhos, quatro são homens, sendo três casados e um solteiro; e das oito mulheres entrevistadas, três são casadas e as outras cinco ficaram viúvas há vários anos. Mas que sentido essas últimas mulheres atribuem à perda dos companheiros?

O sentido encontrado nas narrativas para a viuvez foi a reconstrução da vida. Depois de todo o sofrimento causado pela morte do companheiro e um período de luto, percebem que a vida tem que continuar, o tempo não para. A reconstrução após a viuvez significa continuar sozinha uma vida que estava alicerçada no par marido-esposa, mesmo que o casal não tivesse uma relação ideal. A morte do companheiro, leva a viúva a ocupar um lugar social desconhecido e a maneira que ela vai lidar com essa nova condição pode tomar rumos diversos, desde o isolamento, como também a construção de uma vida participativa em grupos de terceira idade, na Igreja e na família mais ampla. 
No caso das viúvas entrevistadas, depois da morte dos esposos elas passaram a viver sozinhas em suas casas ou mudaram para a casa dos filhos. Nenhuma das cinco viúvas entrevistadas casou novamente. Talvez porque o sentido atribuído ao casamento continue aquele de quando elas se casaram: formação de uma família, o desejo da maternidade. E como isso elas já conquistaram, casar após a viuvez não se inscreve novamente como projeto em suas vidas.

Apenas Ana traz uma compreensão um tanto diferente quanto a possibilidade de se relacionar afetivamente com alguém. Ela diz que hoje sente falta de um companheiro, e que "a vida poderia ser melhor se ela tivesse um companheiro" (Ana, 78 anos). Mas conta que só agora, na velhice, pensou que poderia ter se casado outra vez, pois quando ficou viúva, com "quarenta e poucos anos", isso não passava pela sua cabeça. Por isso, depois da morte da filha, há dois anos, ela aconselhou o genro a procurar outra esposa, pra que na velhice não se arrependa, como aconteceu no seu caso.

Pois eu, pra falar a verdade, sinto mais falta de um marido, de um companheiro. Porque, por causa de baile, eu fico tão, assim, a gente vai nos baile, mas não tem graça. Porque não tem marido, não tem companheiro pra dançar. Então se a gente tivesse um companheiro era melhor.

[A senhora chegou a pensar em casar novamente?]

Antes eu não quis. Agora que eu to pensando, que se eu tivesse casado com os quarenta e poucos anos que eu tinha, pode ser que ele tava vivo e a gente vivia mais bem. Bem melhor, eu acho que vivia melhor! Na época eu não quis, eu só pensava, não adianta, não adianta. $E$, falar bem a verdade, não tinha uma pessoa que eu quisesse casar, não tinha! Eu não saía à parte nenhuma (Ana, 78 anos).

Mas a viuvez apresenta um processo de reconstrução da pessoa, que agora tem de aprender a viver só, como também buscar novas formas de se relacionar com o mundo e com as pessoas que compõem as redes sociais que os cercam. Com a chegada da velhice muitos velhos passam a frequentar novos espaços, como por exemplo, os bailes dos grupos da terceira idade frequentados pela mesma Ana, que reclama a falta de um companheiro, justamente porque não tem um par pra dançar.

A morte do esposo foi descrita por Vitória de forma muita intensa, como o marco da substituição do papel social de esposa, para o papel de viúva.

Daí uma noite eu me lembrei que eu era viúva, eu não tinha lembrado que eu era viúva sabe, mas eu chorei a noite inteirinha! $O$ O. (filho) com a D. (nora) dizem que eu tava dormindo e tava chorando. Eu tava morando no O. naquela época. Eles levantavam, iam me acudir, falar comigo, chacoalhar. De repente, eu tava chorando de novo. Dormindo e 
chorando! Eu lembrei que eu era viúva, ai meu Deus do céu! Que coisa mais triste que tem na vida da gente, é saber que perdeu o companheiro, é muito triste. (Vitória, 79 anos).

As lembranças de Vitória sobre a morte do marido demonstram que, ao se perceber viúva, ao se colocar nessa nova condição sua dor aumenta ainda mais. A partir desse momento, as lágrimas não são somente pelo marido, que se foi, mas também por ela, que ficou e que precisa enfrentar esse novo lugar, agora demarcado pela viuvez. As interações e os espaços mudam com a viuvez. E, além disso, uma morte tão próxima, como a do companheiro faz o sujeito questionar a proximidade da própria morte ou quanto Ihe sobra de vida. A vida é colocada em xeque, com a certeza da sua efemeridade.

Mas a experiência da viuvez também toma outros rumos e as novas formas de sociabilidade vivenciadas por essa situação também fazem com que as mulheres percebam uma dimensão positiva, às vezes mais significativa que a própria solidão provocada pela perda do companheiro. Essa dimensão positiva da viuvez é a independência alcançada pelas mulheres após a morte dos maridos. No estudo de Peixoto (in DEBERT \& GOLDSTEIN, 2000: 298) sobre a sexualidade experimentada na velhice por mulheres que nasceram nas primeiras décadas do século $X X$, a morte do companheiro pode significar desde o sofrimento intenso até o sentimento de liberdade. Segundo a autora na "viuvez-libertação", a morte do marido significa a libertação da tutela masculina, que antes do casamento era exercida pelo pai.

Em nosso contexto, o sentimento de independência aparece em três, das cinco viúvas pesquisadas. Duas delas quando perguntei sobre a possibilidade de se casarem novamente:

Não, nunca quis. Em casa sozinha é melhor, não se incomoda com nada não. Meu marido era muito ciumento, não podia sair quase de casa. Não podia conversar com ninguém. Não foi fácil a minha vida até ali (Carmem, 73 anos, viúva há 19 anos).

Dolores também sublinha essa ideia:

Pois, eu até gostava de ter uma companhia pra cuidar da gente, mas não acha. Achar uma rabuja, arrumar sarna pra se coçar não adianta. Se for pra pegar, que seja uma coisa que preste, que ajude, não que estorve. Se fosse alguém, uma boa companhia pra gente morar sozinho nós dois. Eu nunca mais namorei ninguém. Porque quando a gente vai na dança, tem sempre mais mulher. E onde a gente sai, esses que tão aí... Deus o livre! (Dolores, 86 anos, viúva há 26 anos). 
Já o sentimento de liberdade e independência de Ana, se apresenta com clareza quando ela expõe a melhora da qualidade de vida alcançada na velhice, em comparação com a vida que levava quando era mais jovem:

(Hoje) Eu me considero independente, porque eu faço o que eu quiser. Assim, quando resolvo alguma coisa, por exemplo, que eu quero ir a algum lugar, se eu quero fazer alguma coisa... faço mesmo!

$[\ldots]$

Porque antes quando a gente era casada a gente não se mandava, era o marido que mandava na gente. $E$ depois que ele faleceu, eu me senti mais independente (Ana, 78 anos, viúva há 30 anos).

Diante das posições manifestadas por essas mulheres podemos afirmar que nesse contexto, a viuvez significou a conquista de uma liberdade que elas jamais experimentaram na juventude. O lugar social de onde falam as nossas narradoras foi construído por circunstâncias históricas específicas, demarcadas pela desigualdade de gênero, refletida no espaço concedido à mulher na sociedade e, principalmente, no papel reservado a elas no casamento. Diante disso, foi possível atentar para o papel significativo da viuvez na experiência de envelhecimento, e os sentidos diversos atribuídos a esse evento, ligados à reconstrução das suas vidas, que vai desde a solidão até a independência suscitada pela morte do cônjuge.

\section{VIDA NO ASILO}

Uma das possibilidades de pensar as formas de sociabilidade engendradas pelo envelhecimento foi apresentada por dois de nossos entrevistados, seu Euclides, de 68 anos e Dolores, de 86 anos, e tratam das relações desenvolvidas no interior de uma instituição asilar. Já no início das suas entrevistas, eles deixam claro a dificuldade de conviver no asilo, a disputa pelos espaços, o estabelecimento das regras e as intrigas. Mas o interessante, é que apesar de ambos apresentarem essas reclamações, há uma grande distância entre as imagens que foram pintadas por cada um deles em relação a esse espaço.

Para Euclides, o asilo significa amparo, cuidado, um espaço demarcado pelo suporte às necessidades básicas da pessoa, como alimentação, segurança, acompanhamento fisioterapêtico, entre outros. Ele conta que o que o faz permanecer no 
asilo é o fato de encontrar nesse lugar o necessário pra estar bem. Ali ele faz sessões de fisioterapia, e completa

aqui nós ganhamos tudo, mais de 24 horas por dia, nós temos comida boa, roupa de cama, tudo! Uma coisa ou outra a gente completa, senão tem tudo. Então é isso que segura a gente aqui no lar (Euclides, 68 anos).

Há quatro anos morando no asilo, ele o considera sua casa. É possível afirmar que a visão que Euclides construiu sobre o asilo foi influenciada pela sua trajetória, um homem que viveu sempre sozinho, não teve casa própria, não se casou, nem teve filhos, e aos 64 anos de idade percebeu-se impossibilitado de continuar a morar sozinho. Foi então que resolveu mudar para o asilo, mas não porque se sentiu velho, e sim por conta dos problemas de saúde, que comprometeram por completo a sua independência. Euclides tem um problema grave de visão que o deixou quase cego e ainda, havia fraturado uma das pernas, que mesmo após cirurgia, acabou deixando sequelas que o obrigam a utilizar uma bengala. Nesse caso, a mudança para o asilo teria inaugurado um novo sentido para a vida: sua valorização como pessoa e o cuidado com a saúde, principalmente em relação ao afastamento da bebida:

O que tem de bom é cuidar da saúde, com essa vida que eu levava eu não cuidava da saúde, hoje aqui (no asilo) a gente vê como vale a pena, por causa da idade, como vale a pena se cuidar, cuidar de si (Euclides, 68 anos).

No caso de Euclides, o asilo se apresenta como um espaço fértil para experiências que ele jamais pensou experimentar:

Certa vez, fiz um papel de velhinho no teatro de final de ano, gostei muito e isto me fez bem, foi uma experiência muito gratificante [...] Foi no final de ano, parece que eles chamavam de Natal Luz, uma coisa assim, então eu fazia o papel de velhinho, e um "piazotão" filho de uma senhora que trabalha aqui fez o piazinho. Foi muito bom, uma coisa tão simples, tava lotado esse salão, foi uma coisa brilhante, o povo ai gostou [...] Fácil num foi, porque a gente tinha que praticamente dublar... e eu sem enxergar direito... mas o povo entende, que nós velhinhos... não vai esperar uma.... E pra mim foi uma experiência muito boa, porque eu sempre fui assim meio solitário, eu não tinha coragem pra nada né, e entrei nessa com a professora R., ela dava aula aqui pros nossos internos, então ela e outros que bolaram isso aqui (Euclides, 68 anos).

Ao contrário, dona Dolores, que mora há cinco anos nesse mesmo asilo, tem uma visão completamente diferente da apresentada por Euclides. Para ela, o asilo é um lugar de passagem, e somente aceita permanecer nesse espaço enquanto não consegue outro lugar pra ficar. 
Dolores morou sozinha por muitos anos, mas isso só depois que as três filhas saíram de casa e o marido faleceu. Assim como Euclides, também mudou para o asilo por conta de problemas de saúde, ela tem artrose e hipertensão, e depois de ter sofrido um desmaio percebeu que não poderia continuar a morar sozinha na sua casa, e até que a filha, na qual morou de início, tratasse um problema de saúde e pudesse recebê-la novamente, decidiu passar uns tempos no asilo.

Segundo Dolores, quem olha de fora para o asilo, acha que é tudo muito bom, "maravilha pra quem não vê as coisas (de dentro). Mas eu, pra mim, não tem nada de maravilha aqui, nada, nada" (Dolores, 86 anos). A imagem que construiu sobre o asilo é a de um lugar solitário e hostil, gerada pela dificuldade que os idosos sentem em se relacionar uns com os outros internos e também com os profissionais que trabalham nesse espaço:

A própria dona da casa, ela chega, e não diz 'bom dia' pra gente. Passa assim, como se a gente fosse lixo! E ainda diz que é pra tudo se abraçar, porque é dia dos namorados, e é pra tudo se abraçar e se beijar. Como a gente vai abraça e beija uma pessoa que não abre a boca nem pra dizer um 'bom dia', nem olha direito pra gente? Eu não! Eu abraço uma pessoa que me gosta, ou que eu não vejo a tempo, mas não ali tudo dia. Isso não é comigo, isso é fingimento! É pessoa de três, quatro caras numa só. Tudo isso, olha, enche a gente! Tivesse um canto, onde ninguém possa incomodar a gente, era o lugar melhor que tem (Dolores, 86 anos).

Ela conta ainda que no asilo "todo mundo xinga, a enfermeira xinga, tudo... Não tem quem não xingue" (Dolores, 86 anos). O que está colocado também nessa dificuldade de convivência no asilo são as relações de poder contidas nesse ambiente, onde o interno não decide praticamente mais nada sobre a sua vida, pois as regras já estão postas e ele tem apenas que segui-las. Nesse caso, o asilo poderia ser pensado como uma instituição total:

um local de residência e trabalho onde um grande número de indivíduos com situação semelhante, separados da sociedade mais ampla por considerável período de tempo, levam uma vida fechada e formalmente administrada" (GOFFMAN, 1974: 11).

O que segundo Goffman, significa dizer que tais lugares são espaços sociais fechados, onde regras minuciosas são colocadas em prática no sentido de limitar e homogeneizar as atividades diárias dos internos. Esse esforço de redução sistemática da autonomia individual levaria, gradativamente, à "mortificação do eu" (GOFFMAN, 1974), ou seja, enquanto ator social, o conjunto de papéis com os quais 
um velho asilado poderia contar em seu "eu" torna-se restrito na medida em que a instituição é menos aberta para o mundo exterior.

Sendo assim, Dolores pouco frequenta as áreas coletivas do asilo, e diz preferir o sossego do quarto. Quando mudou para lá, teve que escolher os poucos móveis e objetos que levaria consigo: a cama, o guarda roupas, a máquina de costura e a mesinha de cabeceira, na qual está a imagem de Nossa Senhora do Perpétuo Socorro. Dolores prefere permanecer a maior parte do tempo em seu quarto porque ele representa a ligação com o passado. Os objetos presentes no quarto demarcam sua trajetória trabalhadora, esposa, mãe, dona de casa, avó - e atuam na manutenção da sua identidade como pessoa. Esses pertences são a conexão de Dolores com a pessoa que ela foi e alimentam o projeto de voltar a ser, no instante em que retornar à sua casa.

Para ela, o asilo é um lugar de passagem, e diante dessa representação, manifesta durante toda a entrevista a sua decepção em estar morando ali. Podemos dizer que, se há um projeto que dá significado e orienta a vida de Dolores, é a sua intenção de sair do asilo:

Eu queria ta morando em outro lugar, porque aqui, a gente ta aqui... Não sei porque, aqui a gente não é feliz como é pra ser.

$[\ldots]$

Eu não gosto de morar aqui e não quero morrer aqui (Dolores, 86 anos).

Quando pergunto pelos seus desejos para o futuro, Dolores me responde que o maior deles é encontrar uma cuidadora, para que possa voltar para casa. Sob a lente da nossa entrevistada "não tem nenhum lugar como a nossa casa. Em casa você faz o que você quer, ninguém ta xingando (Dolores, 86 anos).

Ferreira (1998), ao apresentar uma discussão sobre a relação existente entre memória e construção da identidade social na velhice, afirma que a casa pode ser entendida como um elemento físico que representa a ligação com a família, no caso de Dolores a família nuclear que ela construiu com o marido e as três filhas. Ainda segundo Ferreira, o sentido que assume o espaço doméstico e os objetos de uma vida inteira é o de um elo materializado com outros tempos, cujos sinais sobrevivem para reforçar a memória, elemento estabilizador em um contexto descontínuo (FERREIRA in BARROS, 1998: 215).

A casa pode ser entendida como um espaço simbólico que se integra ao indivíduo, e deste modo pode ser pensado como um elemento que auxilia na manutenção da 
identidade social na velhice. Nessa medida, a angústia que Dolores sente em ter que permanecer no asilo se torna mais compreensível, pois o processo de construção da identidade social do idoso que já se encontra abalado pelo lugar reservado aos velhos na sociedade contemporânea, se acentua a partir do momento que ele é retirado da casa e do convívio cotidiano com amigos, familiares e com a comunidade.

Dolores conta que gostava muito de cozinhar e também sempre teve "folhagens" na sua casa, das quais adorava cuidar, mas no asilo, nenhuma dessas práticas é permitida: "Eu gostava de cozinhar, mas aqui nem uma comida a gente pode fazer. Nós somo proibido de entrar na cozinha" (Dolores, 86 anos). As relações de poder são percebidas nessas situações, que demonstram os internos do asilo perdem sua autonomia, tendo que sujeitar- se às regras impostas pela instituição. Após cinco anos, tudo o que sobrou das atividades que Dolores fazia antes de mudar para o asilo foi o crochê, as orações à Nossa Senhora do Perpétuo Socorro e a missa diária, acompanhada pela televisão. Mais que a mudança da rotina, a consequência de toda essa situação foi a destituição de Dolores de sua condição de sujeito. As práticas cotidianas mudaram, 0 espaço físico não é mais o da sua casa, a rede social ficou reduzida e a relação com a família foi restringida às visitas ao asilo, que com o passar dos anos vão se tornando cada vez mais escassas. À medida que o tempo foi passando, os laços se romperam e Dolores foi sendo retirada do circuito de convivência familiar. Sua fala remonta uma situação que ilustra com clareza a perda do seu lugar social e o sofrimento que isso the causa:

Mais tristeza de a gente ta sozinha, ta aqui... [Choro] Porque hoje em dia, os novo
é uma coisa, não querem nada com os velho, que os velho sempre perturbam em
tudo que é coisa. É muita bagunça agora, não tem mais respeito como era
antigamente, os próprios filhos, os netos, tudo... Eu tenho um neto que era muito...
e é até meu afilhado. Daí ele pegou uma mulher lá de não sei aonde, Piauí acho,
um lugar longe. Ele mora, morava ali perto, daí eles foram pra lá, pois ele não veio
nem me dizer tchau. Isso dói pra mim. Porque ser neto, e eu ajudei ele muito, e
ele ir tão longe e não vim me dizer tchau. Tudo isso dói. [choro] (Dolores, 86
anos).

Esse olhar corrobora a discussão sobre o asilo, realizada por Elias (2001), que demonstra que, nos séculos passados, o envelhecimento e a morte eram circunstâncias vividas no ambiente familiar, presentes no cotidiano das pessoas. Com a modernidade e as transformações nas formas de família e do trabalho, essas práticas foram demarcadas por uma elevada institucionalização da velhice e por uma predominância da família nuclear, levando os velhos a uma situação de isolamento, tratados com impessoalidade, 
por especialistas que os acompanham até a morte. Esse é o caso, diz Elias, dos velhos que são colocados em instituições asilares, obrigados a estabelecer novas relações sociais,

a admissão em um asilo normalmente significa não só a ruptura dos velhos laços afetivos, mas também a vida comunitária com pessoas com quem o idoso nunca teve relações afetivas. [...] Muitos asilos são, portanto, desertos de solidão (ELIAS [1983] 2001: 85 e 86).

A partir disso, podemos entender a dificuldade que Dolores tem pra conviver no asilo, com pessoas que não tem nenhum laço afetivo, longe da casa, da rotina e da companhia das pessoas com quem sempre conviveu. O trecho a seguir apresenta os conflitos vivenciados no dia-a-dia pelos internos do asilo:

Tinha uma aqui, agora mandaram embora, me levou três vez lá no escritório, por causa de nada. Vivia enchendo o saco que a gente queria ser 'grandes coisa'[...] Mas chateava... Deus o livre o que eu passei com essa mulher. Só Deus sabe! Daí mandaram ela embora, porque era só mexerico. Então, desse tempo dela, eu já vinha pro quarto, meio sozinha, ficava na sala de televisão e depois vinha pro quarto, pra não entrar em embrulho. É que eu, se me xingam eu já respondo, eu não fico quieta. A gente não ta aí pra ficar aguentando desaforo de qualquer "pé rachado". Por sorte, foi um milagre que Nossa Senhora do Perpétuo Socorro, de tanto que eu pedi, mandaram ela embora. E assim, tem outros também. Mas a gente... deixa. Esse C. também foi um deles. No dia de São João, eu queria benzer uma vela, naquele tempo a televisão tava na sala de janta. Daí ele mudando (de canal) pra lá e pra cá. Eu disse: Deixe lá na missa, que eu quero que benza minha vela. Ele disse: Eu não sou da tua família! Eu respondi: Eu também não queria, Deus me livre de você ser da minha família. Então é assim... (Dolores, 86 anos).

Diante do exposto, podemos utilizar mais uma vez Norbert Elias, quando analisa o papel do asilo no processo de envelhecimento. O velho é um moribundo, na medida em que está mais próximo do fim da vida, e desta maneira, aparece aos olhos da sociedade moderna quase como um elemento premonitório da morte de quem os espreita. Considerando o tabu que se construiu sobre o morrer na nossa civilização, o velho e o moribundo foram processualmente retirados do espaço público, e transferidos para um espaço privado, longe dos olhares de uma sociedade que nega e teme a morte e a velhice.

Para Elias, o desenvolvimento da civilização e a pacificação interna dos indivíduos provocada pelo monopólio da violência, fizeram com que desaprendêssemos a conviver com a dor, a debilidade e a morte. E por isso, nem como espectadores, suportamos lidar com estas experiências. Assim, é cada vez mais frequente que as pessoas passem o final 
dos seus dias solitária e silenciosamente, sem odores, em asilos e hospitais. Acompanhados por médicos e enfermeiros, que numa rotina totalmente institucionalizada, tornam o morrer um acontecimento amorfo, des-ritualizado e afastado dos vivos.

\section{OUTRA VELHICE}

Apesar da legislação brasileira, com a política nacional do idoso e o Estatuto do Idoso, definir o início da velhice aos 60 anos de idade, as narrativas coletadas na pesquisa de campo demonstraram que a velhice aparece ligada a vários fatores, sendo a idade um deles, mas não o mais importante, nem o único. O estudo de Ana Bassit (2002) com histórias de vida de velhas, confirma essa característica e afirma que "a idade cronológica por si só não é suficiente para explicar o envelhecimento, assim como é difícil precisar quando uma pessoa começa a envelhecer ou se torna um adulto" (BASSIT, 2002: 177). Tendo isso em vista, ela conta que na sua pesquisa foram enfatizados os "eventos e experiências da vida adulta dessas mulheres, que estavam relacionados com as formas pelas quais elas vivem o envelhecimento, sendo que estas podem ou não ter alguma correlação com a idade cronológica" (BASSIT, 2002: 177).

As entrevistas realizadas com os idosos de Mafra-SC também demonstraram que a velhice não tem data certa pra começar, e que ela só pode ser pensada se relacionada à condição do velho em relação ao exercício das atividades rotineiras, à possibilidade de movimentar-se e desenvolver algum trabalho, ou dependência com a necessidade de um cuidador. Essa questão demonstra que para compreendermos a velhice temos que olhar para as experiências de envelhecimento dos sujeitos. Sobre este ponto, Alves (2002) afirma que "a análise da experiência nos conduz a problematizar o processo em que a vivência de algo se constitui e ganha expressão" (ALVES, 2002: 154).

Essa outra velhice que se depreende de suas narrativas, possui uma concepção sutil sobre o que é ser velho, uma forma não pronunciada nas narrativas, mas que aparece na análise das experiências cotidianas e se localizam na contramão da imagem negativa historicamente construída em nossa sociedade.

Para Rabelo, Alves e Souza (1999: 11), problematizar a experiência significa assumir que a maneira como os indivíduos compreendem e se engajam ativamente nas situações em que se encontram ao longo de suas vidas não pode ser deduzida de um 
sistema coerente e ordenado de ideias, símbolos ou representações, já que "O conhecimento através do qual se vive não é necessariamente o conhecimento através do qual se explica a vida". Essa condição pode ser evidenciada na pesquisa de campo com os velhos, que trouxeram a contradição entre a compreensão que eles têm da velhice e a forma que eles experimentam essa etapa de suas vidas.

Essa questão foi evidenciada pela pesquisa de campo, que demonstra que a velhice não é somente um tempo de perdas - apesar de ser essa a visão predominante. As entrevistas trazem elementos para pensamos a possibilidade de uma "outra" velhice, compreendida através das experiências vividas dos sujeitos, e não pelo discurso imposto na contemporaneidade sobre o que é ser velho.

A velhice como tempo de conquista toma formas variadas nas narrativas, mas em geral ela está ligada ao aumento do poder aquisitivo dos velhos, em especial daqueles que conquistaram o benefício previdenciário da aposentadoria rural (SUGAMOSTO, 2003). Mas a experiência dessa outra velhice, mais positiva e alicerçada nas experiências individuais, também pode ser encontrada em outros temas, como os projetos para o futuro, a participação no grupo de terceira idade, atividades que preenchem o dia-a-dia dos velhos entrevistados e a comparação que eles fazem entre o passado e o hoje, tempo de velhice.

Vitória, por exemplo, vai realizar uma cirurgia para a retirada de catarata, ela diz que pinta e faz crochê tão bem quanto a neta, só precisa melhorar a vista. Para Vitória, a velhice aparece como continuidade das habilidades e gostos que cultivava desde jovem, e além disso, envelhecer não significa interromper o aprendizado de coisas novas:

\footnotetext{
Como ta aí essa pintura (pintura na toalha da mesa), isso daí tudo eu sei, e faço muito bem. Essas coisas aí foi a L. (neta) que fez. Eu pinto igual ela e faço crochê, por isso que eu quero tratar da minha vista pra eu pintar melhor.

$[\ldots]$

E eu leio muito, ainda aprendo alguma coisa. Eu gosto, eu adoro ler. Por isso que eu vou trabalhar com a minha visão, que já ta me atrapalhando... (Vitória, 79 anos).
}

Dona Dolores, apesar da condição de abandono que relatou ao mudar para o asilo, descreve sua intensa participação no grupo de terceira idade durante anos: "E daí fui rainha do grupo de terceira idade de Rio Negrinho e fui aqui também, fui rainha da terceira idade, agora, ano passado" (Dolores, 86 anos). Do ponto de vista da sexualidade, ela 
conta ainda que, recentemente, foi pedida em namoro "com a idade que eu tenho, tudo, até tem um homem que veio, até me trouxe esse buquê de flor ali, ele queria namorar comigo" (Dolores, 86 anos). A presença do desejo na velhice também aparece na fala de Joaquim: "Eu gosto de andar bem vestido, isso daí faz parte, as mulher olham pra gente!" (Joaquim, 74 anos). Nesses dois casos, o desejo despertado no outro significa a continuidade das performances sociais. O velho busca a continuidade das relações sociais, da interação com os outros indivíduos. Uma outra forma de vivenciar a velhice, conta Sebastião, é valorizar as situações cotidianas, pois viver bons momentos não significa ser jovem ou totalmente saudável, mas a alegria está nas pequenas coisas que cada um gosta de fazer: "Alegria, se eu tiver lidando com terra, música ou pescaria, eu esqueço de comer" (Sebastião, 83 anos). Se tiver fazendo o que gosta, os problemas desaparecem.

Para Lourdes, chegar na velhice é uma vitória:

A história da vida da gente é a luta. Que a gente tem uma luta tão grande, tão pesada, que a gente sofreu bastante pra chegar nesse ponto, né. Agora que a gente tá aposentado, tá velhinho, tá mais melhor a vida do que aquela correria que a gente tava antes (Lourdes, 78 anos).

A comparação que estabelece entre a juventude e a velhice, coloca esta última como tempo de conquista merecido depois das dificuldades que enfrentou durante a vida. Como já apresentado no primeiro capítulo, para Carmem a vida também teria melhorado à medida que foi ficando mais velha:

\begin{abstract}
[A senhora gosta de morar sozinha?]
Eu gosto. Eu prefiro isolada do que no meio do povo. Eu gosto de ficar sozinha. A minha vida melhorou quando eu fiz mais idade, acho que em tudo. A gente não precisa mais trabalhar, trabalha quando quer. Sai quando quer e faz o que quer. Não como quando você tem a família que você é obrigada a fazer as coisas. Melhorou em tudo (Carmem, 73 anos).
\end{abstract}

De certa forma, a imagem de uma velhice positiva também tem sido um discurso presente na sociedade contemporânea, através das expressões "velhice saudável" e da própria ideia de "terceira idade", como tempo de conquistas, prazer, lazer, entre outros. Mas a pesquisa de campo demonstrou que o discurso dominante ainda coloca o velho como inativo, dependente e doente, sendo essa a visão que predominou nas narrativas quando os entrevistados falaram sobre a velhice. Haveria portanto uma dissonância entre o discurso sobre a velhice - essencialmente negativo, como símbolo da morte social do 
indivíduo - e a maneira que os velhos vivenciam suas práticas cotidianas. Diante dessa dissonância entre a experiência de envelhecimento e as representações sociais da velhice, destacamos que a velhice é uma experiência plural, e igualmente são as imagens construídas sobre ela. Essa constatação também foi verificada por Britto da Motta em seus estudos sobre a velhice, segundo ela, estaríamos passando por uma transição onde a imagem social da velhice está melhorando, mas

na realidade, ainda coexistem as duas imagens: a tradicional, 'naturalizada', do velho inativo, respeitável mas inútil; e a nova imagem, mais dinâmica e participante, embora apenas em determinadas situações sociais (BRITTO DA MOTTA in MINAYO \& COIMBRA JR, 2002: 48).

Sobre essa convivência de olhares discordantes sobre a velhice, Minayo e Coimbra Jr (2002) chamam a atenção para a ambiguidade vivenciada pelo próprio indivíduo que envelhece, considerando que essa etapa da vida traz liberdade para o sujeito em relação à sua vida, e ao mesmo tempo uma situação de dependência, enfrentada quando o corpo não se movimenta da mesma maneira que fazia antes. A velhice "é simultaneamente o tempo do orgasmo da vida e da liberdade e o tempo da medida do possível e da dependência. Tudo concomitante e tudo diferenciado pela trajetória individual" (MINAYO \& COIMBRA JR, 2002: 13).

Nessa perspectiva, a pluralidade das concepções da velhice que encontramos entre os idosos e até mesmo dentro de uma mesma narrativa, corroboram a ambiguidade da velhice discutida por Minayo e Coimbra Jr (2002), que coloca o idoso numa situação imprecisa, "entre a liberdade e a dependência". Isso demonstra que o fenômeno social do envelhecimento é muito mais complexo do que parece, fato que pode ser verificado através dos significados construídos sobre a velhice, positivos ou negativos, de ganhos ou de perdas, que foram apresentados pelos sujeitos da nossa pesquisa.

\section{REFERÊNCIAS}

ALVES, P. C. Nervoso e experiência de fragilização: narrativa de mulheres idosas. In: MINAYO, M. C. \& COIMBRA JR, C. E. A. (orgs.) Antropologia, Saúde e Envelhecimento. Rio de Janeiro: Fiocruz, 2002.

BASSIT, A. Z. Histórias de mulheres: reflexões sobre a maturidade e a velhice. In: MINAYO, M. C. \& COIMBRA JR, C. E. A. (orgs.) Antropologia, Saúde e Envelhecimento. Rio de Janeiro: Fiocruz, 2002.

BRITTO DA MOTTA, A. Envelhecimento e sentimento do corpo. In: MINAYO, M. C. \& COIMBRA JR, C. E. A. (orgs.) Antropologia, Saúde e Envelhecimento. Rio de Janeiro: Fiocruz, 2002. 
DEBERT, G. G. A dissolução da vida adulta e a juventude como valor. In: Horizontes Antropológicos. Porto Alegre, ano 16, n. 34, p . 49-70, jul/dez 2010.

DEBERT, G. G. O velho na propaganda. In: Cadernos Pagu (21), p. 133-155, 2003.

ELIAS, N. A solidão dos moribundos seguido de "Envelhecer e morrer". Rio de Janeiro: Jorge Zahar, 2001.

FERREIRA, M. L. M. Memória e velhice: do lugar da lembrança. In: BARROS, M. M. L. (org) Velhice ou terceira idade?: Estudos antropológicos sobre identidade, memória e política. Rio de Janeiro: Fundação Getúlio Vargas, 1998.

GOFFMAN, E. Manicômios, Prisões e Conventos. São Paulo: Perspectiva, 1974.

MINAYO, M. C. \& COIMBRA JR, C. E. A. (orgs.) Antropologia, Saúde e Envelhecimento. Rio de Janeiro: Fiocruz, 2002.

NERI, A. L. Envelhecer num país de jovens: significados de velho e velhice segundo brasileiros não idosos. Campinas: Ed. UNICAMP, 1991.

PEIXOTO, C. E. Histórias de mulheres, de envelhecimento e sexualidade. In: DEBERT, G. G. \& GOLDSTEIN, D. M. (orgs.) Políticas do corpo e o curso da vida. São Paulo: Sumaré, 2000.

RABELO, M.; ALVES, P. \& SOUZA, I. Experiência de doença e narrativa. Rio de Janeiro: Fiocruz, 1999.

SUGAMOSTO, M. Velhice e benefício previdenciário entre os agricultores familiares do município de Colombo - Paraná. Dissertação de Mestrado. Curso de PósGraduação em Sociologia. Setor de Ciências Humanas, Letras e Artes Universidade Federal do Paraná: Curitiba, 2003. 